\title{
Trauma Informed Practice and Care: Implications for Field Instruction
}

\author{
Carolyn Knight ${ }^{1}$
}

Published online: 21 June 2018

(c) Springer Science+Business Media, LLC, part of Springer Nature 2018

\begin{abstract}
This article summarizes the evolution in thinking about trauma and its impact on those who have experienced it. The nature of trauma-informed (TI) practice and care and implications for field instruction are then explained. This discussion is based upon the assumption that skills of social work field instruction that already have an evidence base lay the foundation for TI field instruction. Composite case examples drawn from the author's experiences as a field liaison, a practitioner who works with trauma survivors, and an instructor in the generalist practice curriculum illustrate methods and skills of field instruction from a trauma informed perspective.
\end{abstract}

Keywords Field instruction $\cdot$ Trauma $\cdot$ Trauma informed practice $\cdot$ Trauma informed supervision $\cdot$ Trauma informed field instruction

\section{Introduction}

In 2001, Harris and Fallot introduced the term "traumainformed" to refer to social, behavioral, and mental health services that account for the possibility that clients may have experienced some form of past trauma. Since then, an everexpanding body of conceptual and empirical literature has further delineated the trauma-informed perspective, the core characteristics of which are: trust, safety, choice, collaboration, and empowerment. A trauma-informed (TI) orientation conforms to the defining principles of social work. However, this orientation has yet to be routinely integrated into field and classroom curricula (Knight 2015; Berger and Quiros 2014; Levenson 2017). Further, field instructors often are unfamiliar with requisites of a trauma-informed orientation and their implications for practice and supervision. This problem is compounded by the lack of guidelines for traumainformed supervision, generally (Knight 2018; Berger and Quiros 2016; Mattar 2011).

This article summarizes the evolution in thinking about trauma and its impact on survivors. The trauma-informed perspective and its implications for field instruction are then explained. The author argues that skills of field instruction

Carolyn Knight

knight@umbc.edu

1 School of Social Work, University of Maryland Baltimore County, 1000 Hilltop Circle, Baltimore, MD 21250, USA that already have an evidence base lay the foundation for TI field instruction. Composite case examples drawn from the author's experiences as a field liaison, a practitioner who works with trauma survivors, and an instructor in the generalist practice curriculum illustrate methods and skills of field instruction.

\section{The Nature of Trauma}

Trauma and its aftereffects have received considerable attention from researchers and practitioners alike, beginning almost 40 years ago, resulting in significant advancements in understanding of the nature of trauma and its impact on those who experience it.

\section{Emphasis on Precipitating Event}

The earliest investigations of trauma and its impact focused on two different lines of inquiry: the experiences of veterans returning from the Vietnam War and the impact of childhood abuse (Courtois and Gold 2009). The focus expanded to natural and human-made disasters like the Oklahoma City bombing in 1995, the terrorist attacks in the United States in 2001, and Hurricane Katrina in 2005 (Scheeringa and Zeanah 2008; van der Kolk 2007). Sociopolitical events like civil wars, genocide, and human trafficking prompted further 
refinements in the understanding of trauma (Courtois and Gold 2009; Haans and Balke 2018).

Emphasis was placed on understanding the traumatic impact of a precipitating event. Traumatic exposure was found to be consistently associated with an array of social, psychiatric, psychological, behavioral, and physical problems. Researchers also sought to identify the relationship between trauma exposure and psychiatric problems (Brown et al. 2005; Garno et al. 2005; Mulvihill 2005; Randolph and Reddy 2006). In 1980, the American Psychiatric Association's third edition of the Diagnostic and Statistical Manual introduced a new diagnostic category, Post-Traumatic Stress Disorder (PTSD). The most recent, fifth, edition of the DSM (APA 2013), replaced the PTSD diagnosis with a new, broader diagnostic category, Trauma and Stressor-Related and Dissociative Disorders.

A different line of theoretical and empirical inquiry focused on changes in cognition. Constructivist self-development (CSD) theory addressed distortions in thinking about the self- characterized by feelings of powerlessness and worthlessness, and of others- in the form of mistrust, experienced by survivors of childhood trauma (McCann and Pearlman 1990). CSD theorists also noted how childhood victimization negatively impacted individuals' feelings of mastery- or self-capacities- regarding maintaining connections to others, establishing a stable sense of self and identity, and managing affect (Brock et al. 2006). Distortions in thinking about others were presumed to undermine the individual's ability to form secure attachments (Waldinger et al. 2006). CSD constructs were expanded from a focus on childhood victimization to address challenges faced by survivors of other forms of trauma. Research findings indicated that trauma exposure resulted in diminished feelings of power, control, and safety, and heightened feelings of fear (Cloitre et al. 2005; Giesen-Bloo and Arntz 2005; Kolts et al. 2004).

\section{The Experience of Trauma is Unique to the Individual}

Constructivist self-development theory and the research it prompted led to the realization that individuals exposed to a similar- or even the same- traumatic event experienced it in their own unique way based upon personal, social, and cultural variables (Elliott and Urquiza 2006; Ullman and Fillipas 2005). Traumatic exposure was seen as a psychological event as well as a physical experience. This realization led to efforts to identify factors that increased or mitigated the risk of being traumatized.

\section{Risk and Protective Factors}

Individual and community support has emerged as a powerful variable that may mitigate or increase the risk of traumatization in response to a stressful event (Feinauer et al. 2003; Ruggiero et al. 2004; Twaite and RodriguezSrednicki 2004; Whiffen and MacIntosh 2005). Social support is important both at the time of exposure to trauma and long-term, as individuals struggle with aftereffects (Sippel et al. 2015). This factor is multi-dimensional and includes validation and understanding, acceptance, affirmation, and availability of appropriate resources. The absence of support, which includes blame and/or accusation, continued exposure to the experience, and the lack of acknowledgement of the impact of the event, places survivors at greater risk of experiencing the social, behavioral, emotional, and physical symptoms associated with traumatization.

Prior emotional functioning may either intensify or mitigate the impact of a traumatic event (Andres-Hyman et al. 2004; Bradley et al. 2005). Individuals with pre-existing mental health problems are at greater risk of being traumatized. Emotional, psychological, and psychiatric problems that are common responses to traumatic exposure may have preceded the exposure, or at least have been exacerbated by it (Breslau 2002).

\section{Adversarial and Post-traumatic Growth}

Researchers also examined how individuals who have been exposed to potentially traumatic events benefited from their experiences. Benefits have been found to include: reordering of priorities, an enhanced or new sense of spirituality, a deeper appreciation for life and for loved ones, and increased feelings of self-efficacy, empathy, and concern for others (Bonanno 2004; Linley and Joseph 2004; Tedeschi and Calhoun 2004). Research also indicates that when individuals can identify positive aspects of their traumatic experience, they are likely to experience fewer negative long-term consequences (Linley and Joseph 2004).

\section{Trauma and Neurobiology}

A recent advancement in the understanding of trauma is the recognition that trauma exposure results in neurobiological changes that interfere with the brain's ability to process trauma and affects the body's stress response systems (Nemeroff and Binder 2014). Ongoing research substantiates the role that these maladaptive brain processes play in explaining symptoms that had been viewed as purely psychological, emotional, and/or psychiatric. Physiological changes-including increased heart rate, respiration, and blood flow- in response to stress serve an adaptive function by allowing the body to rapidly respond to threat (Perry 2016). However, continued traumatic exposure or to an event that overwhelms the body's stress response system ultimately compromises the body's regulating systems including memory and affect. Research also indicates trauma exposure 
in childhood- particularly when it is ongoing- affects brain development and can lead to permanent neurological damage in the same regulating systems (Nemeroff and Binder 2014; Perry 2016).

\section{Indirect Exposure to Trauma}

Studies of clinicians who work with survivors of trauma reveal that they are themselves at high risk of being indirectly traumatized. Three reactions have been discerned: secondary traumatic stress, vicarious trauma, and compassion fatigue. These terms often are used interchangeably, but each refers to a distinct manifestation. In this article, the term indirect trauma is employed to refer to the overall impact that working with trauma survivors has on clinicians.

The first two manifestations of indirect trauma mirror those of survivors. Secondary traumatic stress refers to symptoms clinicians working with trauma survivors experience that are with consistent with PTSD: persistent, intrusive thoughts and images of clients; hypervigilance; re-experiencing the client's trauma in recollections and dreams, and hyperarousal (Bride 2004). In the most recent DSM (APA 2013), the expanded stress disorders diagnosis includes secondary traumatic stress. The term vicarious trauma refers to changes in cognition that lead to clinicians adopting a worldview characterized by suspicion, pessimism, and powerlessness (Cunningham 2003, 2004; Pearlman and Saakvitne 1995; van Deusen and Way 2006). These cognitive changes parallel those experienced by trauma survivors themselves and stem from practitioners experiencing indirectly clients' vulnerability and powerlessness in the face of horrific events and/or interpersonal victimization. Compassion fatigue can and does occur in many practice contexts and reflects clinicians' inability to empathize with clients. It is particularly likely to occur among practitioners who work with trauma survivors due to the emotion toll that results from listening to survivors' narratives and witnessing their distress firsthand (Adams et al. 2006; Berzoff and Kita 2010; Figley 1995).

Indirect trauma is seen as an inevitable consequence of working with trauma survivors (Cieslak et al. 2014). Therefore, emphasis is placed on practitioners being proactive in mitigating and managing its effects. Indirect trauma is different from burnout and countertransference, but it may lead to one or both phenomena (Berzoff and Kita 2010; Salston and Figley 2003).

\section{Risk and Protective Factors}

Indirect trauma appears to be higher among professionals who have less education, are newer to their jobs, and have the most and least experience working with trauma survivors
(Harr and Moore 2011; Molnar et al. 2017). In the author's study (Knight 2010) of social work students and their field instructors, virtually all participants evidenced signs of indirect trauma. For example, on a standardized measure of vicarious trauma, social work students scored higher than a sample of trauma therapists overall and on nine of ten subscales. This included measures of trust in self and others, personal safety, and control.

There is some evidence that clinicians who experienced childhood trauma are at higher risk of experiencing indirect trauma (Baird and Kracen 2006; Nelson-Gardell and; Harris 2003). It is unclear whether previous exposure to other forms of trauma predisposes practitioners to indirect trauma, since empirical inquiry has narrowly focused on childhood victimization.

An organizational climate that validates and normalizes workers' reactions mitigates the risk, while one that is perceived as unsupportive increases it (Brockhouse et al. 2011; Dombo and Blome 2016). Lower risk is associated with organizational and supervisory environments that promote self-care and convey to staff that ameliorating indirect trauma is an organizational responsibility as much as an individual one (Hensel et al. 2015; Layne et al. 2011; Salloum et al. 2017; Sprang et al. 2017).

\section{Vicarious Resilience}

Vicarious resilience- or vicarious posttraumatic growth- has been observed among clinicians working in varied practice contexts (Barrington and Shakespeare-Finch 2013; Cosden et al. 2016; Frey et al. 2017; Molnar et al. 2017). Consistent with the research of adversarial growth in trauma survivors, researchers have attempted to identify ways in which clinicians benefit from working with trauma survivors. Positive outcomes include enhanced appreciation for one's advantages in life, a re-ordering of personal goals and priorities, increased sense of professional competence and resourcefulness, and heightened capacity for compassion and empathy. Affirmation of strength and resilience also has been found to exist among clinicians who are themselves survivors of trauma (Killian et al. 2017).

\section{Trauma-Informed Practice and Care}

The trauma-informed conceptualization recognizes that "any person seeking services or support might be a trauma survivor... [Treatment must] recognize, understand, and counter the sequelae of trauma to facilitate recovery" (Goodman et al. 2016, p. 748). Epidemiological studies have found that most adults have been exposed to at least one event that could be characterized as traumatic (Beristianos et al. 2016; Gillikin et al. 2016). Further, a history of trauma exposure, 
especially in childhood, is disproportionately high among clinical populations in mental health, substance abuse, forensic, domestic violence, child welfare, homeless, and sexual assault settings, among others (Alvarez et al. 2011; Glad et al. 2017; Helpman et al. 2015; Rossiter et al. 2015).

While TI "practice" and "care" often are used interchangeably, practice is more accurately applied to clinical intervention, while care refers to the organizational context within which services are provided to clients. TI practice requires an organizational climate that supports it through the assignment of caseloads, availability of TI supervision, and support for self-care (Bassuk et al. 2017; Conover et al. 2015).

\section{Core Principles}

Trauma-informed practice is based upon five principles that reflect the research findings summarized previously (Berger and Quiros 2016; Conover et al. 2015; Goodman et al. 2016). The principles reflect "the direct opposite conditions of persons who have experienced traumatic events" (Hales et al. 2017, p. 318).

Since trauma survivors often experience the world—and, in many cases, other people - as unsafe, safety is an essential feature of TI practice. This includes physical and emotional safety. Physical safety considerations include the location and nature of office furnishings, comfort of agency public spaces, and assurances of privacy. Emotional safety depends upon a working relationship in which clients experience validation, understanding, and support. Safety is interdependent with trust, the second principle, which requires clinicians to establish and uphold clear and consistent boundaries, protect confidentiality to the extent that is possible (and explain ahead of time when confidentiality may need to be violated), and maintain open and honest communication (Knight 2015; Becker-Blease 2017). Trustworthiness requires cultural awareness, since cultural identity influences individuals' experience of trauma exposure (Berger and Quiros 2014; Mattar 2011). Trust also includes helping clients trust themselves and develop the self-capacities needed to manage feelings and successfully address problems in living.

A third characteristic of TI practice is empowerment. The working relationship, itself, should be empowering, allowing clients as much control as possible over their goals and the means to achieve them. Regardless of the specific focus of intervention, emphasis is placed upon helping clients achieve greater mastery over their lives. Client empowerment depends upon clients having choices, the fourth characteristic of TIP. This requires that the worker adhere to core social work ethics: informed consent, clients are the experts of their lives, and respect for cultural identity. Finally, collaboration between worker and client reinforces client choice and empowerment.

\section{Implications of Trauma-Informed Principles for Social Work Practice}

Social work practitioners, educators, and researchers acknowledge the importance and necessity of integrating trauma-informed principles into the delivery of social work services. However, insufficient resources and continued misunderstanding of and confusion surrounding the application of a trauma-informed perspective have undermined implementation efforts. Therefore, research indicates that trauma-informed practice and care remain ideals rather than reality in most social work practice settings (Bassuk et al. 2017; Becker-Blease 2017; Branson et al. 2017; Conover et al. 2015).

In settings that provide services to clients in the immediate aftermath of trauma exposure, TI practice helps clients make meaning of their experience and develop ways of coping with associated behavioral, emotional, social, and psychological problems. Emphasis is placed upon promoting resilience and mitigating long-term negative effects (Burton et al. 2015; Kirst et al. 2016). These settings are best viewed as trauma specific, focused, or centered.

Most survivors of trauma are seen in practice settings that are neither trauma-focused nor specific (Jones and Cureton 2014). These settings- child welfare, forensics, health, school, mental health, homeless services, family services, addictions, and the like- are the ones in which social workers are most likely to be employed and social work students to be placed. In these settings, trauma survivors' concerns are likely to be associated with current problems in living rather than the past trauma that may explain and be associated with them (Becker-Blease 2017; Berthelot et al. 2014; Branson et al. 2017; Gillikin et al. 2016). TI practice in these settings requires that social workers adhere to the five core principles and understand "the ways in which current [client] problems can be understood in the context of past [trauma exposure]" (Knight 2015, p. 26). Social workers are likely to struggle with how to address past trauma when their practice is focused on, for example, addiction, child protection, or homelessness. If underlying trauma is dismissed, not recognized, or is responded to in a way that is uninformed, this increases the risk of re-traumatization and invalidates clients' experiences.

\section{Integrating Trauma-Informed Principles into Field Instruction}

Trauma-informed field instruction requires that field instructors be well-versed in trauma theory and research, as well as the principles of TI practice. In settings that are not traumaspecific, which are common for generalist and foundation year social work students, field instructors must learn how they and their students can work within their agency-defined 
role and still adhere to the five TI principles. Without this understanding, social work students and their field instructors are likely to overlook the role that trauma plays in the present-day challenges faced by their clients as the following scenario demonstrates:

Mark was placed in the public defenders office. He was tasked with collecting relevant history from clients awaiting sentencing that would be presented to the court in advance of their sentencing hearing. He meets with each of his clients once, usually in a detention facility. When Mark met with Travis, who had been charged with assault with a deadly weapon, the client disclosed that his mother's boyfriends "did sex stuff" with him. In his meeting with his field instructor, Mark said that he wanted to pursue what Travis meant by this but didn't think he should since he was "just supposed" to collect information that might help the client in court. His field instructor agreed that he made the right choice. Mark, however, believed that he let his client down.

Mark's assessment is correct. While it was beyond the scope of his role and purpose to encourage Travis to elaborate upon his comment, Mark's avoidance of the disclosure invalidated the client's experiences. Mark's field instructor failed to appreciate how Travis's possible sexual abuse as a child might factor into his current problems with the law and how this might affect the outcome of his trial.

Contrast the previous example with the following:

Sandy is placed in a housing and rehabilitation program for homeless veterans. She has been working as a case manager with Tim, a 45-year-old Army veteran who has been homeless for more than 2 years. Tim also has an addiction to opiates and alcohol. Tim has been in the program for 1 month and is likely to remain a resident for another 3-4 months. She meets with him weekly to see how he is progressing on the goals that he and the clinical team have established. During these meetings, Tim has begun to disclose his memories of combat in the Mideast, which included seeing friends blown-up from improvised explosive devices and women and children killed by allied forces. When Sandy meets with her field instructor, Matthew, she tells him she does not know how to help Tim: "I'm not a therapist just a case manager". Sandy also becomes teary-eyed as she relates to Matthew some of the experiences that Tim shared with her. Matthew assures Sandy that she does have the skills needed to help Tim with what he has disclosed, and he also validates how difficult it is to hear stories such as Tim's:

Matthew: A lot of our clients have seen and done terrible things. That's why a lot of them end up home- less and addicted. And it's really hard to hear their stories. Over the years, I've learned ways to deal with my feelings. I'm thinking we could take some time to help you do the same. No matter where you work or who you work with, your feelings can get the best of you. But, how about we first talk about how you can be- really how you are-being helpful to Tim. Sandy: Great, because I feel like I'm not qualified to help him!

Matthew: You're not giving yourself enough credit! First off, you listened to his recollections and expressed your concern for him and sadness for what he experienced, right? That means you validated his experience and what it meant for him. By letting him talk about this, you are helping him manage his feelings.

Sandy: But he needs so much more than I can provide. Matthew: Well, I agree, that your role doesn't allow you to provide him with in-depth counseling, but as his case manager, you do have the ability to validate his concerns, identify resources that can help him deal with his war experiences, and support the positive changes he has been making. Those are all incredibly important for Tim.

Matthew had not been trained in trauma-informed practice or supervision. However, his work with Sandy is consistent with TI principles. Trauma-informed supervision simultaneously addresses supervisees' potential for indirect trauma and assists them in responding appropriately and in non-traumatizing ways to clients with histories of trauma. The content of field instruction exists within a climate that reflects safety, trust, empowerment, choice, and collaboration.

Safety and trust seemed to already exist in this field instruction relationship, as evidenced by Sandy's willingness to disclose her feelings about her work. Matthew uses his own experiences with indirect trauma to normalize Sandy's reactions and suggests they spend time identifying ways to manage them, which is empowering and reinforces safety and trust. He does not intend to tell her what to do to manage her feelings; he will help her decide this for herself, consistent with collaboration, empowerment, and choice. Finally, Matthew helps Sandy see how she can practice within her role as a case manager and still address in a meaningful way Tim's underlying experience with trauma.

Trauma-informed field instruction builds upon three basic responsibilities that are required for effective field instruction. These functions are interdependent and include educating the student, creating a learning environment that is conducive to learning, and attending to students' personal and affective reactions to their work and the supervisory relationship. 


\section{Education: Convey Knowledge of Trauma and Trauma-Informed Practice}

Since social work education continues to lag in its teaching about trauma and trauma-informed practice, it may fall to field instructors to assume this responsibility. Research indicates that instructors' educational responsibilities must be tailored to their students' unique learning needs (Bogo 2005). Findings further substantiate that field instructors' educational tasks are most effective when they occur in a climate of mutuality, in which students are active participants in their learning (Miehls et al. 2013). Consistent with TI principles, the field instructor and student should engage in a collaborative learning endeavor.

Knowledge of the following topics is critical to students' ability to work with survivors of trauma:

1. The meaning of trauma in clients' lives;

2. The short- and long-term effects of trauma exposure;

3. The relationship between trauma exposure and challenges that clients currently experience;

4. The impact that trauma exposure has on clients' beliefs about self and others;

5. The impact that these beliefs have on clients' willingness and ability to engage in a working relationship with students; and

6. Intervention techniques that promote the five principles of TI practice consistent with students' roles within the agency.

The following example comes from an outpatient drug treatment program. The agency has made concerted efforts to adhere to TI principles in service delivery, paying particular attention to a history of sexual abuse, since this is common among many of its clients. Erin has been assigned to conduct an intake for a new client, Sylvia, who is selfreferred for an addiction to cocaine. This is the first time that Erin will be conducting an intake on her own, though she has observed and participated in several intake interviews with her field instructor, Susan, and other agency social workers. The intake includes several questions designed to elicit clients' experiences with trauma generally, and sexual abuse in particular. Erin and Susan meet in advance of the intake to prepare Erin for this client encounter.

Susan: So, you're seeing Sylvia this afternoon. I'm wondering how you are feeling?

Erin: Nervous! But also excited. I'm glad I've gotten to see how you do this. It makes me feel more like I won't mess up.

Susan: Good to hear! I'm wondering what your thoughts are about asking Sylvia about any possible abuse history? I've been conducting these interviews for a lot of years, but I still find it hard to ask about this stuff. I hate to bring up a topic that might be painful for the client. I find myself holding my breath- hoping that when I ask, the client will say no!

Erin: I'm kind of feeling the same way. I know that if our clients have been abused, it's important we know about it as soon as possible to make it part of our treatment plan. But, I'm scared that if she tells me something did happen, I won't know what to say.

Susan: Okay, suppose Sylvia does disclose she was abused in some way? Where do you go from there? Remember we've talked about how important it is to validate our clients' experiences and feelings? That's a place to start. How might you go about doing that?

At this point, Erin and Susan discuss ways that Erin could respond to her client potential disclosures.

Susan's actions reflect a solid evidence base and are consistent with TI field instruction. First, she paved the way for Erin to be more independent by allowing her to sit in on and participate in sessions with clients. Encouraging students to observe professionals and debrief afterwards assists them in understanding the "nuanced" aspects of practice (Bogo 2015, p. 319). Second, Susan helps Erin prepare for her interview using a variant of role playing, fostering Erin's ability to integrate theory and research with practice and enhancing her confidence (Bennett and Deal 2012; Bogo 2015; Miehls et al. 2013).

Third, Susan refines Erin's understanding of the needs of trauma survivors as well as how to approach the topic in a sensitive way in the intake interview. Rather than lecturing Erin, Susan engages in a "mutual reflective dialogue" (Bogo 2015, p. 320). Fourth, Susan encourages Erin to play an active role in her learning and asks her to identify her learning needs-what she believes she needs to know before she meets with Sylvia for the first time.

\section{Supervisory Environment: Creating a Climate that Promotes Learning}

Framing the field instructor-student relationship as a reciprocal one reflects the TI principles of safety and trust. Evidence underscores the importance of attending to the relational aspects of the field instruction relationship (Bennett et al. 2012; Ornstein and Moses 2010). A supervisory relationship characterized by a secure attachment promotes learning as well as self-reflection and independent thought and action. Bennet and Sak's (2006) description of the "ideal" student scenario is consistent with trauma-informed supervision:

[Students] are willing to ask for assistance and...they accept feedback and instructions...in a flexible manner, shifting from dependence to exploration...Self- 
reflective about their interventions and their own professional development, their presentations about their work are organized and coherent. They are able to discuss tough issues and examine their personal roles in their clinical relationships...(p. 674).

A supervisory environment that promotes safety and trust allows for exploration of students' experiences with indirect trauma. This environment also is one that empowers students. A collaborative relationship between student and field instructor enhances feelings of mastery and self-efficacy (Bennett and Saks 2006; Bogo 2015). This also encourages the student to be self-directive in identifying learning needs, a reflection of the TI principle of choice. The previous supervisory session between Susan and Erin continued, with Susan asking:

Before we wrap up our session, how do you think you'd feel if Sylvia tells you she was abused? Have you thought about that?

Erin: I think I'd feel sad, sorry for her, angry for her. Susan: All normal and understandable feelings, right? (Erin nods) And you and I are going to keep talking about how our work affects us, because it sure does, as you can tell from what I've told you before about my reactions.

Erin: I'm finding that out! (Smiles)

Susan's disclosures about her struggles with indirect trauma normalize and validate Erin's reactions, indicating she attends to the relational aspects of her supervisory relationship with Erin (Ornstein and Moses 2010). Erin's willingness to discuss her anxieties about her upcoming meeting with her client suggests that Susan has created an environment that Erin experiences as supportive and one in which she can openly discuss her concerns (Strozier et al. 2000).

In a previous example, the field instructor, Matthew, also revealed to his supervisee, Sandy, his experiences with indirect trauma. Consistent with considerations associated with self-disclosure in social work practice, Susan's and Matthew's disclosures in supervision are limited and intentional; they validate and normalize their supervisee's reactions. In both instances, the supervisors' self-disclosures fostered their students' willingness to acknowledge and discuss their affective reactions to their work. This is consistent with research findings that reveal that supervisor self-disclosure is associated with supervisee comfort and willingness to disclose and discuss sensitive and difficult topics (Bennett et al. 2012; Mehr et al. 2010, 2015).

While not obviously apparent from the two excerpts, Susan and Matthew maintain appropriate boundaries, having clarified from the beginning of the placement how they and their students would work together (Ganzer and Ornstein 2004). Their disclosures about their reactions to their work with survivors pave the way for their students to do the same. The field instruction relationship is not a therapeutic one, but the "interpersonal worlds" of student and field instructor (Ornstein and Moses 2010, p. 108) are important considerations when discussing work with trauma survivors (Berger and Quiros 2016; Bride and Jones 2006).

Working with trauma supervisors will inevitably generate strong affective reactions for both field instructors and their students. Therefore, a notable aspect of trauma-informed supervision is understanding and making use of parallel process. It has long been accepted that interactions between supervisors and their supervisees will mirror reactions to and interactions with clients. Contemporary conceptualizations of parallel process recognize its inevitability and bidirectionality (Bennett et al. 2012; Miehls 2010). This dynamic is no longer viewed solely or even mostly as a manifestation of transference or countertransference. Authors observe that parallel process reflects the subtle interplay of the personalities of the supervisor and supervisee as they genuinely engage with one another and with clients (Miehls 2010). Further, it need not be a disruptive force in the supervisory alliance. When this is the case, however, the field instructor must address its manifestations directly. This is especially important when it is the field instructor's reactions that are at play.

Whether disruptive or not, parallel process provides the field instructor with unique teaching and learning opportunities (Strozier et al. 2000). As this dynamic is examined in supervision, both student and field instructor deepen their understanding of themselves and one another. The field instructor's actions in this regard model for students how to handle similar situations when they surface in their work with clients (Miehls et al. 2013; Schamess 2012). They also are consistent with the trauma informed principles of collaboration and empowerment. "Supervision relationships [in trauma work] are most meaningful, when co-created, and where supervisor and supervisee anticipate a reciprocal process that may reflect enactments of treatment scenarios that surface in the supervisory relationship" (Miehls 2010, p. 377).

In this last example, the setting is an inpatient psychiatric facility. The field instructor, Ricardo, addresses tension that has surfaced in his relationship with his student, Tanya. The student has been working with Marcus, a patient on the forensic unit, preparing a report for his court appearance on charges of assault with a deadly weapon. In previous supervisory sessions, Tanya emotionally described what she has learned about Marcus's childhood: he witnessed the murder of an older brother; was physically abused by his father; and was placed in numerous foster homes in which he was physically and sexually abused. In their current meetingwhich occurred 3 weeks before Tanya's placement was ending- she reported that she had promised Marcus she would 
accompany him to his court hearing, which was to occur after the placement ended.

Ricardo: Whoa, Tanya, we need to talk about this. I understand you want to be there for Marcus for his trial, but once you leave us, you're no longer his social worker.

Silence

Ricardo: Tanya.....so.... what are you thinking? You look pissed.

Tanya: Marcus has nobody! Not one person! He's told me that I'm the first person who has been nice to him, been there for him. I have to go! It's not fair to not let me go!

Ricardo: I'm not keeping you from going. I am reminding you that, when you terminate, your work with your clients is over, and I' $m$ afraid that includes Marcus.

Silence

Ricardo: Tanya, I know this is tough. I know you care about him. And, yes, I know that Marcus has had no one, and you have been there for him. You seem angry with me? Maybe for reminding you of boundaries? Tanya: I just don't think boundaries should matter in this case. I have been his social worker for 4 months. You don't understand how hard it's been on him! I don't think you're being fair to him or me.

Ricardo: I get that you're upset, and I'm glad you can tell me. I hope you'll consider the possibility that it's not really me you're angry at. Maybe you're angry at the situation- that you can't be there for him when he needs you to be. Angry at all those people that weren't there for him when he needed them. Maybe you're even feeling a little guilty? That you are'abandoning' him when he needs you the most?

Silence

Tanya: I'm sorry. I'm being disrespectful.

Ricardo: Nothing to apologize for! You care about Marcus, and you have to terminate with him at a critical juncture in his life.

Tanya's willingness to reveal her anger to Ricardo suggests that their supervisory alliance promoted honest and open discussion. Ricardo does not respond defensively or in an accusatory manner to Tanya's reactions, consistent with research that indicates that negative reactions or no reaction at all undermine students' learning and the supervisory alliance (Bennett et al. 2012; Ornstein and Moses 2010). Instead, he normalizes Tanya's reactions and validates the understandable feelings of sadness, anger, and guilt that accompany ending her work with Marcus. As their discussion proceeded, Tanya was able to see how her personal feelings for Marcus- which were reasonable under the circumstances- led to a blurring of boundaries. Ricardo also helped Tanya see how she could terminate with Marcus in a way that would minimize feelings of abandonment and empower him to continue with his goals. Traditional conceptualizations of parallel process would frame Tanya's reactions to her client as countertransference and her field instructor as countertransference. As noted, contemporary notions view them as normal and expected components of practice and supervision.

\section{Attend to Students' Reactions: Managing Indirect Trauma}

The field instructor must be proactive in addressing manifestations of indirect trauma. This begins with normalizing and validating students' reactions. It can include making an "affective check-in" (Etherington 2009) a routine aspect of supervision. The field instructor queries students about their emotional responses to their work, and, as needed, offers students an opportunity to discuss reactions that are problematic and may interfere with their work and/or impact their personal lives.

Appropriate use of this strategy requires that students and field instructors have a clear understanding of boundaries as well as a shared understanding of why the check-in and the conversation that may follow are necessary for students' professional development. In an earlier example, the field instructor, Matthew, normalizes his student's reactions by disclosing the challenges he has faced working with traumatized clients. In another case scenario, the field instructor explores her student's possible feelings in advance of the student's meeting with the client, and in the final example, Ricardo directly addresses manifestations of transference. In each instance, students' reactions are normalized, lessening their negative impact.

\section{Conclusion}

Trauma-informed field instruction builds upon supervisory skills that already have a strong evidence-base and are widely acknowledged to further students' learning in the field practicum. School and programs of social work have a responsibility to educate field instructors about trauma, its impact on clients and workers, and the nature of trauma informed practice. TI field instruction can only be effective if supervisors understand the nature of their and their students' practice. Field instructors also must understand how they can integrate the five trauma informed principles into their supervision. Emphasis should be placed on helping field instructors understand how supervisory skills they are already using and that have a strong evidence base fit within a trauma informed context. A straightforward way to foster field instructors' education is to offer continuing education workshops on trauma that meet licensure requirements. 
Trauma-informed field instruction cannot exist without organizational support and a climate that is itself traumainformed (which is often referred to as trauma-informed care) and adheres to and promotes the five TI principles with respect to organizational climate and culture, the treatment of clients and staff, and physical plant. (Bassuk et al. 2017; Conover et al. 2015). This includes reinforcing the need and providing opportunities for self-care as well as other avenues for support for clinicians, administrative staff, and supervisors.

Unfortunately, organizations in which students are most likely to be placed have been slow to embrace trauma informed principles. Therefore, when field instructors engage in trauma-informed supervision, they and their students are likely to be challenged by an organizational environment that does not recognize the unique aspects of working with trauma survivors. Therefore, future efforts must not only be directed at helping field instructors adopt a trauma-informed orientation, but also at advocating that their employing organizations do the same. Most fundamentally, social work education, itself, must become more trauma informed. As social workers become more trauma informed, the agencies and organizations that employ must be encouraged to follow suit.

\section{References}

Adams, R., Boscarino, J., \& Figley, C. (2006). Compassion fatigue and psychological distress among social workers. American Journal of Orthopsychiatry, 76, 103-108.

Álvarez, M., Roura, P., Osés, A., Foguet, Q., Solà, J., \& Arrufat, F. (2011). Prevalence and clinical impact of childhood trauma in patients with severe mental disorders. Journal of Nervous and Mental Disease, 99, 156-161.

American Psychiatric Association (APA). (2013). Diagnostic and statistical manual of mental disorders (5th edn.). Washington, DC: American Psychiatric Association (APA).

Andres-Hyman, R., Cott, M., \& Gold, S. (2004). Ethnicity and sexual orientation as PTSD mitigators in child sexual abuse survivors. Journal of Family Violence, 19, 319-325.

Baird, K., \& Kracen, A. C. (2006). Vicarious traumatization and secondary traumatic stress: A research synthesis. Counselling Psychology Quarterly, 19, 181-188.

Barrington, A. J., \& Shakespeare-Finch, J. (2013). Working with refugee survivors of torture and trauma: An opportunity for vicarious post-traumatic growth. Counselling Psychology Quarterly, 26(1), 89-105.

Bassuk, E. L., Unick, G. J., Paquette, K., \& Richard, M. K. (2017). Developing an instrument to measure organizational traumainformed care in human services: The TICOMETER. Psychology of Violence, 7, 150-157.

Becker-Blease, K. A. (2017). As the world becomes trauma-informed, work to do. Journal of Trauma \& Dissociation, 18, 131-138.

Bennett, S., \& Deal, K. (2012). Supervision training: What we know and what we need to know. Smith College Studies In Social Work, $82,195-215$.
Bennett, S., Mohr, J., Deal, K. H., \& Hwang, J. (2012). Supervisor attachment, supervisory working alliance, and affect in social work field instruction. Research on Social Work Practice, 23, 199-209.

Bennett, S., \& Saks, L. V. (2006). A conceptual application of attachment theory and research to the social work student-field instructor supervisory relationship. Journal of Social Work Education, 42, 669-682.

Berger, R., \& Quiros, L. (2014). Supervision for trauma-informed practice. Traumatology, 20, 296-301.

Berger, R., \& Quiros, L. (2016). Best practices for training traumainformed practitioners: Supervisors' voice. Traumatology, 22, $145-154$.

Beristianos, M. H., Maguen, S., Neylan, T. C., \& Byers, A. L. (2016b). Trauma exposure and risk of suicidal ideation among older adults. The American Journal of Geriatric Psychiatry, 24, 639-643.

Berthelot, N., Godbout, N., Hebert, M., Goulet, M., \& Bergeron, S (2014). Prevalence and correlates of child sexual abuse in adults consulting for sexual problems. Journal of Sex and Marital Therapy, 40, 434-443.

Berzoff, J., \& Kita, E. (2010). Compassion fatigue and countertransference: Two different concepts. Clinical Social Work Journal, $38,341-349$.

Bogo, M. (2005). Field instruction in social work: A review of the research literature. The Clinical Supervisor, 24, 163-193.

Bogo, M. (2015). Field education for clinical social work practice: Best practices and contemporary challenges. Clinical Social Work Journal, 43, 317-324.

Bonanno, G. (2004). Loss, trauma, and human resilience: Have we underestimated the human capacity to thrive after extremely aversive events? American Psychologist, 59, 20-28.

Bradley, R., Schwartz, A., \& Kaslow, N. (2005). Posttraumatic stress disorder symptoms among low-income, African-America women with a history of intimate partner violence and suicidal behaviors: Self-esteem, social support, and religious coping. Journal of Traumatic Stress, 18, 685-696.

Branson, C. E., Baetz, C. L., Horwitz, S. M., \& Hoagwood, K. E. (2017). Trauma-informed juvenile justice systems: A systematic review of definitions and core components. Psychological Trauma: Theory, Research, Practice, and Policy. https://doi. org/10.1037/tra0000255.

Breslau, N. (2002). Epidemiological studies of trauma, posttraumatic stress disorder, and other psychiatric disorders. Canadian Journal of Psychiatry, 47, 923-929.

Bride, B. (2004). The impact of providing psychosocial services to traumatized populations. Stress, Trauma, and Crisis, 7, 29-46.

Bride, B. E., \& Jones, J. L. (2006). Secondary traumatic stress in child welfare workers: Exploring the role of supervisory culture. Professional Development, 9, 38-43.

Brock, K., Pearlman, L., \& Varra, E. (2006). Child maltreatment, selfcapacities, and trauma symptoms: Psychometric properties of the inner experience questionnaire. Journal of Emotional Abuse, 6, 103-125.

Brockhouse, R., Msetfi, R. M., Cohen, K., \& Joseph, S. (2011). Vicarious exposure to trauma and growth in therapists: The moderating effects of sense of coherence, organizational support, and empathy. Journal of Traumatic Stress, 24, 735-742.

Brown, R., Schrag, A., \& Trimble, M. (2005). Dissociation, childhood interpersonal trauma, and family functioning in patients with somatization disorder. American Journal of Psychiatry, 162, 899-905.

Burton, M. S., Cooper, A. A., Feeny, N. C., \& Zoellner, L. A. (2015). The enhancement of natural resilience in trauma interventions. Journal of Contemporary Psychotherapy, 45, 93-204.

Cieslak, R., Shoji, K., Douglas, A., Melville, E., Luszczynska, A., \& Benight, C. C. (2014). A meta-analysis of the relationship 
between job burnout and secondary traumatic stress among workers with indirect exposure to trauma. Psychological Services, 11, 75-86.

Cloitre, M., Miranda, R., \& Stovall-McClough, K. (2005). Beyond PTSD: Emotion regulation and interpersonal problems as predictors of functional impairment in survivors of childhood abuse. Behavior Therapy, 36, 119-124.

Conover, K., Sharp, C., \& Salerno, A. (2015). Integrating traumainformed care principles in behavioral health service organizations. Psychiatric Services, 66, 1004.

Cosden, M., Sanford, A., Koch, L. M., \& Lepore, C. E. (2016). Vicarious trauma and vicarious posttraumatic growth among substance abuse treatment providers. Substance Abuse, 37, 619-624.

Courtois, C., \& Gold, S. (2009). The need for inclusion of psychological trauma in the professional curriculum: A call to action. Psychological Trauma: Theory, Research, and Practice, 1, 3-23.

Cunningham, M. (2003). The impact of trauma work on social work clinicians: Empirical findings. Social Work, 48, 451-459.

Cunningham, M. (2004). Avoiding vicarious traumatization: Support, spirituality, and self-care. In N. Boyd \& Webb (Eds.), Mass trauma and violence: Helping families and children cope (pp. 327-346). New York: Guilford Press.

Dombo, E. A., \& Blome, W. (2016). Vicarious trauma in child welfare workers: A study of organizational responses. Journal of Public Child Welfare, 10, 505-523.

Elliott, K., \& Urquiza, A. (2006). Ethnicity, culture, and child maltreatment. Journal of Social Issues, 62, 787-809.

Etherington, K. (2009). Supervising helpers who work with the trauma of sexual abuse. British Journal of Guidance \& Counselling, 37, 179-194.

Feinauer, L., Hilton, H., \& Callahan, E. (2003). Hardiness as a moderator of shame associated with childhood sexual abuse. American Journal of Family Therapy, 31, 65-78.

Figley, C. (1995). Compassion fatigue: Toward a new understanding of the costs of caring. In B. Stamm (Ed.), Secondary traumatic stress: Self-care issues for clinicians, researchers, and educators (pp. 3-28). Lutherville, MD: Sidran Press.

Frey, L. L., Beesley, D., Abbott, D., \& Kendrick, E. (2017). Vicarious resilience in sexual assault and domestic violence advocates. Psychological Trauma: Theory, Research, Practice, and Policy, 9, 44-51.

Ganzer, E. D., \& Moses, H. (2010). Goodness of fit: A relational approach to field instruction. Journal of Teaching in Social Work, $30,101-114$

Ganzer, E. D., \& Ornstein, E. D. (2004). Regression, self-disclosure, and the teach or treat dilemma: Implications of a relational approach for social work supervision. Clinical Social Work Journal, 27, 231-246.

Garno, J., Goldberg, J., Ramirez, P., \& Ritzler, B. (2005). Bipolar disorder with comorbid cluster B personality disorder features: Impact on suicidality. Journal of Clinical Psychiatry, 66, 339-345.

Giesen-Bloo, J., \& Arntz, A. (2005). World assumptions and the role of trauma in borderline personality disorder. Journal of Behavior Therapy and Experiential Psychiatry, 36, 197-208.

Gillikin, C., Habib, L., Evces, M., Bradley, B., Ressler, K. J., \& Sanders, J. (2016). Trauma exposure and PTSD symptoms associate with violence in inner city civilians. Journal of Psychiatric Research, 83, 1-7.

Glad, K. A., Hafstad, G. S., Jensen, T. K., \& Dyb, G. (2017). A longitudinal study of psychological distress and exposure to trauma reminders after terrorism. Psychological Trauma: Theory, Research, Practice, and Policy, 9(Suppl 1), 145-152.

Goodman, L. A., Sullivan, C. M., Serrata, J., Perilla, J., Wilson, J. M., Fauci, J. E., \& DiGiovanni, C. D. (2016). Development and validation of the Trauma-Informed Practice Scales. Journal of Community Psychology, 44, 747-764.
Haans, A., \& Balke, N. (2018). Trauma-informed intercultural group supervision. The Clinical Supervisor. Available at http://www. tandfonline.com/doi/full/10.1080/07325223.2017.1399495.

Hales, T., Kusmaul, N., \& Nochajski, T. (2017). Exploring the dimensionality of trauma-informed care: Implications for theory and practice. Human Service Organizations: Management, Leadership \& Governance, 41, 317-325.

Harr, C., \& Moore, B. (2011). Compassion fatigue among social work students in field placement. Journal of Teaching in Social Work, 32, 350-363.

Harris, M., \& Fallot, R. (2001). Using trauma theory to design service systems: New directions for mental health services. San Francisco CA: Jossey Bass.

Helpman, L., Besser, A., \& Neria, Y. (2015). Acute posttraumatic stress symptoms but not generalized anxiety symptoms are associated with severity of exposure to war trauma: A study of civilians under fire. Journal of Anxiety Disorders, 35, 27-34.

Hensel, J. M., Ruiz, C., Finney, C., \& Dewa, C. S. (2015). Metaanalysis of risk factors for secondary traumatic stress in therapeutic work with trauma victims. Journal of Traumatic Stress, 28, 83-91.

Jones, L. K., \& Cureton, J. L. (2014). Trauma redefined in the DSM5: Rationale and implications for counseling practice. Professional Counselor, 4, 257-271.

Killian, K., Hernandez-Wolfe, P., Engstrom, D., \& Gangsei, D. (2017). Development of the Vicarious Resilience Scale (VRS): A measure of positive effects of working with trauma survivors. Psychological Trauma: Theory, Research, Practice, and Policy, 9, 3-31.

Kirst, M., Aery, A., Matheson, F. I., \& Stergiopoulos, V. (2016). Provider and consumer perceptions of trauma informed practices and services for substance use and mental health problems. International Journal of Mental Health and Addiction, 15, 514-528.

Knight, C. (2010). Indirect trauma in the field practicum: Secondary traumatic stress, vicarious trauma, and compassion fatigue among social work students and their field instructors. Journal of Baccalaureate Social Work, 15, 31-52.

Knight, C. (2015). Trauma-informed social work practice: Practice considerations and challenges. Clinical Social Work Journal, 43, 25-37.

Knight, C. (2018). Trauma-informed supervision: Historical antecedents, current practice, and future directions. The Clinical Supervisor, 37, 7-37.

Kolts, R., Robinson, A., \& Tracy, J. (2004). The relationship of sociotropy and autonomy to posttraumatic cognitions and PTSD symptomology in trauma survivors. Journal of Clinical Psychology, $60,53-63$

Layne, C. M., Ippen, C., Strand, V., Stuber, M., Abramovitz, R., Reyes, G., et al. (2011). The core curriculum on childhood trauma: A tool for training a trauma-informed workforce. Psychological Trauma: Theory, Research, Practice, and Policy, 3, 243-252.

Levenson, J. (2017). Trauma-informed social work practice. Social Work, 62, 105-113.

Linley, P. A., \& Joseph, S. (2004). Positive change following trauma and adversity: A review. Journal of Traumatic Stress, 17, 11-20.

Mattar, S. (2011). Educating and training the next generations of traumatologists: Development of cultural competencies. Psychological Trauma: Theory, Research, Practice, and Policy, 3, 258-265.

McCann, I., \& Pearlman, L. (1990). Psychological trauma and the adult survivor. New York: Brunner/Mazel.

Mehr, K. E., Ladany, N., \& Caskie, G. L. (2010). Trainee nondisclosure in supervision: What are they not telling you? Counselling \& Psychotherapy Research, 10, 103-113.

Mehr, K. E., Ladany, N., \& Caskie, G. L. (2015). Factors influencing trainee willingness to disclose in supervision. Training \& Education In Professional Psychology, 9, 44-51. 
Miehls, D. (2010). Contemporary trends in supervision theory: A Shift from parallel process to relational and trauma theory. Clinical Social Work Journal, 38, 370-378.

Miehls, D., Everett, J., Segal, C., \& DuBois, C. (2013). MSW students' views of supervision: Factors contributing to satisfactory field experiences. The Clinical Supervisor, 32, 128-146.

Molnar, B. E., Sprang, G., Killian, K. D., Gottfried, R., Emery, V., \& Bride, B. E. (2017). Advancing science and practice for vicarious traumatization/secondary traumatic stress: A research agenda. Traumatology, 23, 129-142.

Mulvihill, D. (2005). The health impact of childhood trauma: An interdisciplinary review, 1997-2003. Issue in Comprehensive Pediatric Nursing, 28, 115-136.

Nelson- Gardell, D., \& Harris, D. (2003). Childhood abuse history, secondary traumatic stress, and child welfare workers. Child Welfare, $82,5-26$.

Nemeroff, C., \& Binder, E. (2014). The preeminent role of childhood abuse and neglect in vulnerability to major psychiatric disorders: Toward elucidating the underlying neurobiological mechanisms. Journal of the American Academy of Child \& Adolescent Psychiatry, 53, 395-397.

Ornstein, E. D., \& Moses, H. (2010). Goodness of fit: A relational approach to field instruction. Journal of Teaching in Social Work, $30,101-114$

Pearlman, L., \& Saakvitne, K. (1995). Trauma and the therapist: Countertransference and vicarious traumatization in psychotherapy with incest survivors. New York: Norton.

Perry, L. (2016). Trauma, neurobiology, and personality dynamics. The Journal of Individual Psychology, 72, 161-167.

Randolph, M., \& Reddy, D. (2006). Sexual abuse and sexual functioning in a chronic pelvic pain sample. Journal of Child Sexual Abuse, 15, 61-78.

Rossiter, A., Byrne, F., Wota, A. P., Nisar, Z., Ofuafor, T., Murray, I., \& Hallahan, B. (2015). Childhood trauma levels in individuals attending adult mental health services: An evaluation of clinical records and structured measurement of childhood trauma. Child Abuse \& Neglect, 443, 36-45.

Ruggiero, K., Smith, D., Hanson, R., Resnick, H., Saunders, S., Kilpatrick, D., \& Best, C. (2004). Is disclosure of childhood rape associated with mental health outcome? Results from a national women's study. Child Maltreatment, 9, 62-77.

Salloum, A., Kondrat, D. C., Johnco, C., \& Olson, K. R. (2017). The role of self-care on compassion satisfaction, burnout, and secondary trauma among child welfare workers. Children and Youth Services, 49, 54-61.

Salston, M., \& Figley, C. R. (2003). Secondary traumatic stress effects of working with survivors of criminal victimization. Journal of Traumatic Stress, 16, 167-174.
Schamess, G. (2012). Mutual transformation in psychotherapy. Clinical Social Work Journal, 40, 10-22.

Scheeringa, M. S., \& Zeanah, C. H. (2008). Reconsideration of harm's way: Onsets and comorbidity patterns of disorders in preschool children and their caregivers following Hurricane Katrina. Journal of Clinical Child \& Adolescent Psychology, 37, 508-518.

Sippel, L. M., Pietrzak, R. H., Charney, D. S., Mayes, L. C., \& Southwick, S. M. (2015). How does social support enhance resilience in the trauma-exposed individual? Ecology \& Society, 20, 136-145.

Sprang, G., Ross, L., Miller, B. C., Blackshear, K., \& Ascienzo, S. (2017). Psychometric properties of the secondary traumatic stress-informed organizational assessment. Traumatology, 23, $65-171$.

Strozier, A. L., Barnett-Queen, T., \& Bennett, C. K. (2000). Supervision: Critical process and outcome variables. The Clinical Supervisor, 19, 21-39.

Tedeschi, R., \& Calhoun, L. (2004). Posttraumatic growth: Conceptual foundations and empirical evidence. Psychological Inquiry, 15, $1-18$.

Twaite, J., \& Rodriguez-Srednicki, O. (2004). Childhood sexual and physical abuse and adult vulnerability to PTSD: The mediating effects of attachment and dissociation. Journal of Child Sexual Abuse, 13, 17-38.

Ullman, S., \& Fillipas, H. (2005). Ethnicity and child sexual abuse experiences of female college students. Journal of Child Sexual Abuse, 14, 67-89.

van der Kolk, B. (2007). The history of trauma in psychiatry. In M. Friedman, T. Keane \& P. Resick (Eds.), Handbook of PTSD: Science and practice (pp. 19-36). New York: Guilford Press.

van Deusen, K., \& Way, I. (2006). Vicarious trauma: An exploratory study of the impact of providing sexual abuse treatment on clinicians' trust and intimacy. Journal of Child Sexual Abuse, 15, 69-85.

Waldinger, R., Schulz, M., Barsky, A., \& Ahern, D. (2006). Mapping the road from childhood trauma to adult somatization: The role of attachment. Psychosomatic Medicine, 68, 129-135.

Whiffen, V., \& Macintosh, H. (2005). Mediators of the link between childhood sexual abuse and emotional distress: A critical review. Trauma, Violence, and Abuse, 6, 24-39.

Carolyn Knight Professor of Social Work, teaches generalist practice and serves as a faculty field liaison. She has many years of experience providing social work services to adult survivors of childhood trauma. She has written extensively about this work as well as about effective field instruction. 